\title{
CARLOS FRANQUI
}

\section{América Latina: mito, utopía, realidades *}

Pensar bien significa aprender a pensar, el mejor maestro del oficio del bien pensar es recobrar la libertad perdida. Digo que la fe, libertad perdida, es pérdida de libertad: fe religiosa, política, filósofica, económica. Como bien decía Sócrates, la duda es madre del pensamiento, la duda es la que puede conducirnos a la libertad. Pienso que los cambios futuros, pasarán por la duda constante, no por la afirmación, que no se cuestiona.

Digo que somos un continente de buenos habladores, contadores y fabuleros, no de pensadores. Dudar es ser libre, dudar es pensar, dudar es decir no. Pienso que nuestro continente necesita muchos $N O$, pocos y raros $S I ́$. Hay que poner en cuestión, analizar, dudar, repensar, cada cosa que se nos ha dicho en el transcurso de nuestras vidas, de nuestras historias.

Hay que oponer un primer $N O$ a la conquista, que como cultura dominante vive todavía, (sin chovinismo, ni demagogia, ino somos nosotros descendientes tanto de conquistadores como de esclavos?). $N O$ al jefazo, al mandón, al héroe -que siempre cobra y cuán cara la cuenta - al caudillo, al patriarca, al general y al doctor, al político ladrón, al obispo y al curita. NO al que nos ofrece el maná del cielo, a Washington, que tampoco puede ser un $S I ́$ a Moscú. NO al poderoso, al oligarca, al comandante. $Y$ un gran SÍ a la libertad, que son todas las libertades concretas y no las falsas palabras.

Cuando digo NO a la iglesia, no hablo de Dios, me refiero a la iglesia como poder temporal, ésa que sobre las ruinas de la vida y culturas de los esclavos indios o negros construyó su poderoso dominio robándole el ánima a tanto pobre indio, esclavo o pobre; ayer como hoy. Se comprende, claro, que quien nada tiene, tenga una fe que le permita sobrevivir, aun si le aliena el alma y a veces el cuerpo. (Y no estoy hablando del viejo concepto marxista, de

* Ponencia lerda en el Congreso del Quinto Centenario del Descubrimiento de América, celebrado en Sevilla en abril de 1988. 
que la religión es el opio de los pueblos - yel comunismo el nuevo paraíso terrenal. Infierno terrenal son los países bajo el socialismo real, que nadie ha podido cambiar y del que todos, incluidos mis compatriotas, quieren huir.).

Pocas instituciones más ambiguas y contradictorias que la iglesia: apoyó la conquista, que fue espada, no cruz; ofrecía Cristos y cielos a los esclavos que iban a morir asesinados por sus conquistadores. Bien respondió Hautey, el indio sabio, al sacerdote que le ofreció el cielo mientras preparaban la hoguera cristiana para quemarlo. Hautey preguntó si eran cristianos quienes lo quemarían y al decírsele que sí, dijo: mejor no ir al cielo en semejante compañía y con un dios que es el oro.

En la conquista, la independencia, la república, con tiranía o con democracia, la iglesia siempre estuvo y se las arreglo para apoyarlas y aparentar que se les oponía, desde el padre De las Casas hasta la Teología de la liberación - que nos ofrece Cristos-Lenin. No señores, declárense marxistas o cristianos, no nos vengan con ese cuento fidelista-cardenalista, de la síntesis entre marxismo, leninismo, fidelismo, cristianismo y aún komeinismo. Y no por razones teóricas, que el Papa, Moscú, Fidel y el Partido en sus documentos oficiales niegan, sino que hablo en nombre de la realidad, de la práctica: Quién puede negar que en todo el mundo comunista las religiones están prohibidas y perseguidas; en la misma Cuba es más difícil encontrar un bautizado que la famosa aguja del bíblico pajar.

No hablo de ateísmo, de Dios o dioses, blancos, indios o negros. Hablo de la historia de la iglesia en América Latina y España. ¿Podemos olvidar en este Congreso conmemorativo que Franco fue bendecido por la Iglesia, y con él sus crímenes? - y no estoy justificando, por supuesto, los crímenes nuestros, de la República. ¿Es que no fueron bendecidos Trujillo y cuanto dictadorzuelo, jerarca, patriarca, oligarca, ladrón, general o doctor, señores de horca y el cuchillo, antes merecedores de la excomunión?

Otra cosa aún, acaso ese desprecio católico por la riqueza -no por los ricos - ¿ ¿no ha sido una de las causas de nuestra pobreza, y en la casa protestante, de riquezas? - sin que se exima al protestantismo, de otras responsabilidades y deshumanizaciones.

Contar la historia como es, es nuestro deber de americanos. El silencio, la mentira, no nos han servido ni nos servirán sobre la iglesia, la conquista, la independencia, los militares, los políticos, la dictadura, la dependencia, la democracia, la revolución.

El $S I ́$ a la democracia, como único gobierno posible, debe ser el $N O$ a cuanto político corrupto y ladrón existe en nuestro con- 
tinente - son tantos que no cabrían en el infierno. NO a tantas deformaciones que ponen en peligro la democracia, que sólo sirven a los golpes militares y a las falsas y trágicas revoluciones.

Debemos ser más críticos con la independencia que con la conquista. La independencia es nuestra primera afirmación, la negación -se supone-de los conquistadores; extraña mezcla de bella utopía: independencia, libertad, república, democracia, unidad americana. En la práctica, como afirmara José Martí, parió no pueblos, repúblicas, sino que engendró campamentos militares.

No disminuimos la grandeza histórica de los independentistas si debatimos las causas y razones de por qué caudillos y generalotes de segunda tomaron el poder en las nacientes repúblicas; eran en realidad nuevos conquistadores disfrazados de revolucionarios.

Entre las causas del fracaso independentista me parece importante señalar que fueron minorías las que se alzaron en armas, que las mayorías se lavaban las manos o, de alguna manera, apoyaban la colonia: véase la historia de Venezuela o la de Cuba. El generalísimo Máximo Gómez al llegar a La Habana y ser recibido por una inmensa multitud dijo con amargura: si toda esta gente se hubiera alzado, hubiéramos acabado con España a sombrerazos.

Ésta de las minorías, es una de las tragedias de la independencia, la democracia, la política y la revolución. Otra es el caudillismo, mal universal heredado de Dios o del Diablo: emperadores, césares, reyes, señores feudales, guerreros, conquistadores, revolucionarios y héroes que todo el mundo ha padecido, de los que una parte de la humanidad se han liberado y otras no. Herencia medieval, románica, hispánica y aún americana, independentista y revolucionaria, que se apoya en realidades materiales y sociales que resisten modernización, industrialización, democracia y cultura política democrática.

Entre las causas del fracaso revolucionario una, no menor, es la de ese prevalecer entre nosotros del fusil ante el pensamiento y las ideas políticas, que me recuerda una discusión de triste memoria, cuando uno de nuestros héroes, hoy en prisión en Cuba, hablaba de grabar ideas en las culatas de los fusiles, a lo que respondíamos, sin ser oídos, por él ni por los otros, que las ideas tenían que estar en las cabezas de los revolucionarios.

Es que nuestros pueblos actúan más que piensan, la acción y el heroísmo, prevalecen sobre las ideas. Es una actitud primitiva, machista de desprecio por la cultura y las ideas, de la que aún está muy permeado nuestro continente. 
Nuestra historia dará un vuelco positivo, por cierto, cuando nos quitemos los espejuelos marxistas, católicos, gringos, medievales y miremos con ojos universales y americanos nuestras complejas realidades.

No siempre hay un totí culpable y otro totí liberador ("el mal viene de afuera y el bien para curarlo también es extranjero"). Otra mentira es la de que todos males nos vienen de nuestra incapacidad latina, negra, india (como somos incapaces por naturaleza, debemos correr al amparo del bravo tío Sam), con lo cual izquierda y derecha, en conflicto sobre los males internos, coinciden en buscar soluciones externas, antes de Washington, ahora de Moscú - vía La Habana.

La historia ha mostrado que ni Washington ni Moscú nos han resuelto nuestros problemas y, cómo éstos son, al menos la mitad, responsabilidad nuestra, sólo a partir de que caminemos con nuestros propios pies y veamos y pensemos con nuestras cabezas, estaremos en condiciones de enfrentarlos. Otra verdad histórica que tenemos que decir a nuestros pueblos es que ningún acto de magia de un caudillo, un dios o una revolución resolverá nuestros problemas de un golpe. Sólo la conciencia y la acción continuada irán cambiando nuestras realidades y, si los políticos mienten por interés $\mathbf{u}$ obligación, los intelectuales independientes debemos decir éstas, que nos parecen verdades evidentes.

Un riguroso análisis crítico que desnude nuestros mundos, no puede olvidar nuestras grandes luchas, progresos y realizaciones, tiene que reafirmar nuestras culturas, sus grandes valores artísticos, literarios, científicos, musicales, poéticos. Si tantas cosas nos separan, hay una lengua que es patria universal, que nos une y exalta, una historia compartida y una inevitable convivencia futura.

Somos un continente joven en lucha con una naturaleza no dominada, como en Europa o los Estados Unidos; la naturaleza todavía domina la ciudad, aún cuando la mayoría de nuestros pueblos ya no viven en campos y montañas, en gran parte arrastrados por la industrialización y las formas vida urbana, hacia periferias marginales e inhumanas, que rodean nuestras metrópolis. Debemos luchar contra la naturaleza para convertirla en ciudad humana y no en "tendópolis" miserables, sin olvidar, como bien decía Le Corbusier, que la ciudad debería ser naturaleza idealizada. Me parece que una de las grandes transformaciones futuras del continente, debería producirse por la creación de ciudades y comunicaciones, incluyendo hospitales y escuelas.

Erradicar miseria, analfabetismo, militarismo, tiranía, son ta- 
reas prioritarias. Para realizarlas necesitamos de reformas agrarias, que afecten enormes tierras no cultivadas, que den la propiedad en forma individual - sabido es que el Estado propietario es tan improductivo como el geófago, y aún más represivo.

Pienso, y aquí aplico una de las pocas experiencias positivas de la revolución cubana, que una alfabetización por parte de la ciudad en el campo, que contribuya a descubrirle su propio mundo, hecha sin demagogia y en forma permanente, que tenga por protagonista la juventud, acompañada de escuelas y maestros, disminuiría muchas de las disparidades existentes entre ciudad y campaña.

Debemos ocuparnos en plantear cómo podría mejorar la sanidad y disminuir los altos porcentajes de mortalidad infantil y el descomunal crecimiento de la población; también prever la capacitación de un cuerpo de enfermeros, sanitarios y médicos, así como la construcción de una red de sanatorios, casas de salud, hospitales y la provisión de medicinas.

A su vez, el inhumano y gigantesco desempleo que padecemos comenzaría a desaparecer con este retorno creativo de la ciudad al campo y la periferia; como pienso que un mínimo y obligatorio subsidio a los desocupados sería ganado con las actividades antes señaladas.

Me parece que uno de los problemas de nuestra América, son esos grandes y peligrosos ejércitos fuente, entre las primeras, de nuestros males. ¿Por qué no aplicar la experiencia de Costa Rica? ¿Por qué no disminuir, tecnificar y dar conciencia democrática a nuestros nuevos oficiales? ¿Por qué no crear facultades militares en nuetras universidades?. Y no se me diga que la disminución y transformación de los ejércitos abrirá las puertas a la revolución o al terrorismo. Esas puertas las abren la miseria, los golpes militares, la corrupción política y el fracaso de las democracias débiles.

Parece evidente que no tenemos con qué pagar esa gigantesca deuda que la banca internacional ha concedido a gobiernos ladrones, que se han robado centenares de miles de millones de dólares, para reinvertirlos en el extranjero, sin hacer ninguna obra útil. Pues negóciese con la banca mundial, dígase claramente, queremos pagar, pero no podemos, estamos dispuestos a pagar el capital, no los intereses; necesitamos cien años para pagar, con el mínimo que podamos extraer de nuestras famélicas economías.' Y sepan que los pueblos de América Latina no se responsbilizarán con otras deudas en el futuro. Queremos obras, no dinero, y con esto nos referimos también a las ayudas de los 
organismos internacionales. Todo esto será posible si creamos una nueva conciencia económica latinoamericana, que no haga el juego a demagogos, a los intereses creados, ni a los políticos fracasados y ladrones.

Cuba ha demostrado que ni el comunismo ni la URSS, resuelven los problemas económicos, al contrario, los agravan; tampoco parece que la inversión del capital extranjero sea motor determinante de la necesaria industrialización de nuestros países. Dado que debemos pensar y repensar, cada mito, negativo o positivo, uno a estudiar es éste de las inversiones extranjeras, con los conservadores, que veían en ellas la salvación económica, y con los progresistas, que creíamos que reforzaban el imperio y la explotación. La realidad desmintió una y otra tesis.

Ahora que América Latina no es tierra preferida de los inversionistas extranjeros, descubrimos que todo el mundo, comprendidos los países comunistas, tienen y quieren desesperadamente más inversionistas y capitales extranjeros. Una verdad es clara hoy, sin riqueza no se puede mejorar la justicia social; la miseria no se puede socializar, la cuestión es producir riquezas y disminuir el hambre y las desigualdades. Otra verdad es la que el Estado no es creador de riquezas.

Hay algunos derechos inalienables, que nuestras futuras repúblicas deberían establecer: subsidio al desempleo, sanidad, educación, retiro. Una parte de las riquezas, obtenidas mediante impuestos al capital y al trabajo, servirían para resolver esos problemas fundamentales, sin asistencialismo, ni burocracia. Todos tendrían derecho a ese mínimo indispensable, pero deberían pagarlo con un mínimo esfuerzo, que sería también fuente de riqueza y de justicia social. Base ésta de un nuevo Estado Social, democrático y reformista, en el que la libertad ha de transformar nuestros países, hoy amenazados de quedar definitivamente marginados de la historia, o de ser futuros campos de batallas de las luchas entre las grandes potencias, que el arsenal atómico ha desplazado del mundo industrial a los continentes pobres.

Nosotros vivimos en América. América, nuestra América es parte de Occidente. El NO a Washington, a intervenciones, presiones y dependencias, era y es una necesidad. Pero sería de ciegos seguir confundiendo a Washington y a los monopolios con la sociedad norteamericana y su democracia. Con las fuerzas democráticas de Estados Unidos tenemos que establecer una relación de amistad, ayuda y comprensión, que puede ser determinante en el futuro. No se pueden negar más los gigantescos 
cambios ocurridos en aquel poderoso país, en los últimos años. El $N O$ a todo acto de gran potencia, no tiene que ser $N O$ a la democracia y a la libertad, al contrario, debe de ser $S I ́$.

El $N O$ al viejo intervencionismo, no puede ser $S I ́$, , al nuevo intervencionismo soviético, presente ya en nuestra América y peligrosamente disfrazado de esa bella palabra de Bolívar y Martí: Revolución; que para ellos era libertad, independencia, democracia, república, unidad americana, y que para los rusos, detentores hoy del monopolio de la revolución mundial, es ser una pobre provincia moscovita, gulag, barbarie, tiranía, miseria. Es con los pueblos del mundo comunista que se rebelan que tenemos que aliarnos, no con sus amos y explotadores.

Por eso digo que tenemos que pensar, dudar, repensar. ¿No es función primordial de la inteligencia pensar?. Resulta vano negar con falsa modestia, que los trabajadores intelectuales somos la vanguardia de ese mundo, mientras con soberbia pretendemos poseer el monopolio del pensamiento. Muchos hombres de talento son artistas, mas no pensadores. Intelectual es todo aquel que cultive el pensar con ejercicio crítico y libre. Hay quienes tienen una extraordinaria capacidad de fabular, pero no para reflexionar; otros son prisioneros de mitos, conveniencias y conflictos, muchas veces entre el corazoncito rojo y la voraz barriga burguesa; otros, conservadores en sus vidas, son progresistas en sus obras. Otros, han sido y son todavía, capaces de decir $N O$ a viejos y nuevos poderes y $S I ́$ al arte, la cultura y la libertad. Decir NO es quizás siempre lo más difícil.

De mi experiencia confieso que, los $S I ́$; que parecían maravillosos, se volvieron desastres; los $N O$, al contrario, son todavía revolucionarios.

\section{Proposiciones al congreso}

-Que este Congreso vuelva a reunirse de forma no oficial, con el propósito de animar un gran debate sobre nuestra historia, vida y realidades;

-Que organice una magna exposición de arte y literatura, a fin de reivindicar tanto clásico desconocido, tanta obra colectiva de valor -como nuestra música; tantas formas de hablar y escribir nuestra lengua común, patrias de la patria universal.

Esa cultura creada, por nuestros pueblos es la reafirmación de que no somos subdesarrollados, aun si somos pobres; es lo mejor de nuestra historia y puede originar el gran impulso que anime cambios del presente y del futuro. 
Sevilla es ciudad madre y este viaje al revés del quinto centenario debe ser un rencuentro iberoamericano. La televisión en directo, usada con inteligencia, pudiera servir para ubicarnos simúltaneamente en los lugares más interesantes de nuestra naturaleza, historia, ciudades, obras y cultura.

El bautizo a nuestra aspiración de constituir la gran comunidad iberoamericana podría ser el de un pasaporte firmado por Colón, nuestros patriotas independentistas y por ese Rey democrático, don Juan Carlos, que por una vez permitiera una entrada sin visa, en América, Iberia y Europa.

Pienso también que deberíamos comenzar una campaña para hacer realidad esa bella expresión de deseo del Primer Ministro, Felipe González, de que para 1992 no haya ningún prisionero en Iberoamérica. 